\title{
Local culture and resistance to shocks in economic forecasts: A case study of Greece
}

\author{
Annie Tubadji $^{*} \cdot$ Vassilis Angelis $^{1} \cdot$ Peter Nijkamp $^{2}$ \\ ${ }^{1}$ University of the Aegean, Chios, Greece \\ ${ }^{2} V U$ University, Amsterdam, The Netherlands
}

Received: 19 September 2014

Revised: 26 January 2015

Accepted: 30 January 2015

\begin{abstract}
This paper offers an analysis of errors in stochastic forecasts in case of economic shocks, on the basis of local intangible investments and historic cultural persistence in Greece. The main objective of the paper is to demonstrate that local culture is a factor of significance for resistance to economic shocks. To operationalize our study, we use two data sources: (i) the European University Institute (EUI) European Regional Dataset (ERD) which offers a timeseries for Greece on a NUTS-III level for the period from 1980 till 2011, containing information about total employment, sectoral employment (where intangible investment related sectors are captured in the analysis), and gross value added; (ii) the Hellenic Ministry of Culture Permanent List of Designated Archaeological Sites and Monuments in Greece. We analyze the relationship of the forecasting errors with sectoral specialization and cultural milieu. We find evidence for a Tieboutian (local culture and local intangible investment related) foundation for the resistance to economic shocks in Greece in the period 2008 - 2011.
\end{abstract}

Keywords: culture, intangible investments, local productivity, forecast, Greece

JEL Classification Codes: Z10, O31, O32, O33, O43, R11

\section{Introduction}

Culture is tacitly recognized as a major factor of interest for regional economic development. Yet, only some aspects of its relationship with regional economic development are known, focusing mostly on effects in times of economic stability.

A prominent topic in the culture and economics relationship has been the link between local culture and local investment in amenities. Tiebout (1956) proposed already more than half a century ago that local cultural differences drive the pattern of local amenities

\footnotetext{
* Corresponding author. E-mail: atubadji@hotmail.com.
}

Citation: Tubadji, A., Angelis, V. and Nijkamp, P. (2014) Local culture and resistance to shocks in economic forecasts: a case study of Greece, Economics and Business Letters, 3(4), 298-308. 
investments. The idea that intangible investments (such as investment in health services, educational services, R\&D and other public goods i.e. non-market services) are driven by local cultural differences (Tiebout 1956) has recently been re-emphasized in studies on the drivers of local innovation and endogenous economic growth (see Schumpeter 1939; Romer 1986, 1990a, 1990b, 1994, Acemoglu and Robinson 2010). Tiebout's hypothesis also assumed a functional link between local economic development on the one side, and migration and local intangible investments on the other side. Such a nexus of investments in innovation and migration is especially prominent in both the classical work of Jacobs (1961) and in recent work by Florida (2002a,b, 2005). Recently, another stream of literature has emerged that pays attention to culture and local development from an economic history perspective and traces events and cultural heritage influences on local economic development (see, for example, Dell 2010).

The recently developed Culture Based Development (CBD) paradigm (see Tubadji 2012, 2013, Tubadji and Nijkamp 2014, 2015) distinguishes the above described two sources of cultural effect into: living culture (a Tieboutian effect) and cultural heritage (a cultural persistence or path-dependence related effect), which are both sources of impacts of local culture on regional development. In recent work by Tubadji and Gnezdilova (2015), cultural attitudes were examined as a driver of local disparities in response to and management of economic shocks. The latter paper examines the pro-socialist voting in Germany as a factor explaining the 'German miracle' effect of flexible labour market responses to the economic crisis, saving thousands of Germans from unemployment through the adoption of proegalitarian labour market policies in the 2007-crisis period. A similar stream of research can be found in, for example, Pedroni et al. (2012).

In the present paper, we aim to push the CBD argument further by examining the two sources of cultural impact in the context of economic shocks, using regional data. We focus on the case of Greece as one of the countries most affected by the recent crisis and especially rich in cultural heritage. Consequently, the main working hypothesis for our study is:

H01: The forecast errors for Greece 2008-2011, occurring under conditions of economic shocks, can be explained, besides standard economic factors, by the current Tieboutian sector specialization (i.e. related to intangible investment) and historic-cultural persistence.

To test the above hypothesis and capture the different aspects of the relevant effects, we analyze data about economic productivity in Greece on a regional level over the past three decades. The structure of the paper is as follows. Section 1 presents briefly the relevant literature and the main Culture Based Development (CBD) inspired hypothesis of our empirical model. Section 2 describes the data used, while Section 3 outlines the estimation strategy. Section 4 presents the estimation results. Section 5 offers concluding remarks.

\section{Methods}

Our empirical approach consists of two steps. In the first step, we obtain a stochastic prediction 1980 - 2007 without culture and examine the forecast error in relation to actual gross value added, specialization and culture in the forecast period 2008 - 2011. In the second step, we check whether the involvement of culture in the stochastic prediction model would improve its predictive power and derive new forecasts for the period $2008-2011$.

For the first step, to address our working hypothesis, we used the below stated model, suggested by Angulo et al. (2014):

$$
\text { ln_empl }=\beta_{0}+\beta_{1} l n \_g v a+\beta_{2} S I+e_{1}
$$


where: ln_empl stands for the natural logarithm of employment in the particular region, In_gva represents the natural logarithm of gross value added in the region, $S I$ is a vector of sector specialization indices, namely the six sector-related dummy variables, which are equal to 1 when the region exhibits a specialization in a particular sector - according to equation (3) presented in our data section $->1$, and equal to 0 , otherwise.

We use model (1) to estimate stochastically a prediction for $\ln \_$empl and its relationship to intangible investments for the period 1980 - 2007. In specific, we use a centered moving average method for de-trending ln_empl, we obtain the trend of the data stochastically through an estimation of model (1) through an OLS regression with fixed time and region effect and then derive the predicted values of ln_empl by using the classical multiplicative model accounting for trend, seasonality and irregularity components (see Shaoa and Nib 2004 for the limitations of the approach).

Next, we proceed to address our hypothesis H01, i.e. to uncover the source of the forecast error in our model. Specifically, we assume that the reason for the difference in our forecast of ln_empl and its actual level during the crisis lies either in the different resistance of the sectors to a crisis and/or in the cultural persistence in the region. To test this rationale, we use ordinary least square with time and region fixed effects, when not involving culture, and only with time fixed effects, when involving the fixed cultural heritage characteristics of the NUTS-III level, instrumentalizing local institutional differences with historic cultural variables in an explicit manner. Thus, we use a culturally augmented version of model (1):

$$
\text { ln_empl }=\beta_{0}+\beta_{1} \ln \_g v a+\beta_{2} S I+\beta_{3} \text { Culture }+e_{2}
$$

The additional regressor in model (2), Culture, is a historic instrumental variable which approximates the local historic path-dependence strength of the cultural milieu through the share of available cultural heritage per square kilometer; finally, $e$ is the standard error term. We use model (2) to address the forecast errors from model (1) as a dependent variable which is to be explained in relationship with sector specialization and culture.

Next, we compare the predictive power of model (1) and model (2) with a simple regression procedure with time and region fixed effects, in order to test whether involving culture in prediction would improve the forecast for 2008 - 2011 or whether culture plays a role in the explanation of the forecast error from model (1), because the cultural milieu is related to the resistance to economic shocks. If the involvement of the cultural heritage instrument in the prediction model increases its power, then cultural heritage is simply one more factor determining stochastically the ln_empl. If however, the predictive power of the model is not significantly affected by the inclusion of cultural heritage variable, and meanwhile if we have found cultural heritage to be a significant regressor that explains the forecast error during the crisis period, these results, considered jointly, will mean that cultural heritage is identified as a factor for the reaction of the economic process in a locality to a shock.

\section{Data}

To address our main working hypothesis, we use two data sources: (i) the European University Institute (EUI) European Regional Dataset (ERD) to quantify employment, sectoral specialization and gross value added as well as the Tiebotian intangible investment; and (ii) the Hellenic Ministry of Culture Permanent List of Designated Archaeological Sites and Monuments in Greece for approximating the historic-cultural milieu.

The EUI/ERD data represent a time-series for Greece for each of the 53 NUTS-III regions for the period from 1980 till 2011, with information about total employment, sectoral employment (where intangible investment sectors can be captured in the analysis), and gross 
value added. This EUI/ERD information is used to inform our variables: logarithm of employment (ln_empl), logarithm of gross value added (ln_gva) and dummy variables for specialization indices. Following Angulo et al. (2014), we obtained the latter through the formula for the share of sectoral employment as a ratio of the share of total employment in a particular locality, namely:

$$
S I=(E s / E s t) /(E r / E t)
$$

where $S I$ stands for specialization index, Es - for employment in the specific sector in a given region, Est - for employment in this sector in the whole country; $E r$ denotes total employment in the region and $E t$ stands for total employment in the country. For every sector we construct a dummy variable indicating its specialization, this variable taking a value of 1 when the SI index for the specific sector exceeds 1 . Thus we obtain six dummy variables for specialization in: si_agri - agriculture, si_ind - industry excluding manufacturing, si_constr - construction, si_trade - wholesale, retail, transport and distribution, communications, hotels and catering, si_fin - financial and business services, and si_non_m - non-market services.

The Tieboutian intangible investment quantification is expected to be captured by the last of the above listed dummy variables - the investment in non-market services, as these include education and health among others, which are major public goods and in this sense they represent intangible investments subject to local cultural relativity.

In addition, using the Hellenic Ministry of Culture Permanent List of Designated Archaeological Sites and Monuments in Greece, we obtain two alternative measures for the quantification of cultural heritage. These are: a historic period specific variable (share of Byzantine cultural heritage per square kilometer), and a more holistic measure of cultural heritage, i.e. the share of castles of all historic periods per square kilometer. The cultural heritage, being reliable as a data source and interesting in its power of a historically exogenous instrument, might be expected to be correlated through cultural tourism with our specialization in trade variable and through a cultural impact on intangible investments with the specialization in non-market services. That is why we examine the correlations between the variables very carefully and base our main prediction model on the reduced form of our model of interest excluding culture. Some comments on the possible reverse causality meaning of the presented result will also be offered in our analysis. Moreover, the relationship between these variables is especially interesting, given the annual data by the Association of Greek Tourism Enterprises (SETE) and the Bank of Greece, show that in 2012, tourism accounts for about $18 \%$ of the GDP of the country and employs more than one fifth of the workforce. In addition, the number of international tourist arrivals has been gradually increasing ever since the beginning of the crisis in 2007. Non-Market services themselves have been growing as part of employment in Greece - representing $17 \%$ of employment in the 1980 and accounting for $27 \%$ in 2011, with a constantly growing trend. Interestingly, share of trade employment grew generally from $23 \%$ to $33 \%$ of employment over the 1980 2011 period, but in the period of crisis 2008-2011 experienced a steady slow fall.

\section{Results}

Our first exploratory look at the data is presented in Figure 1a-b below. As we see, the available time series of about 30 years seems to describe a general trend in employment in Greece, driven by employment specialization in trade and in non-monetary services, while the remaining industries show the employment over time with quite diverse patterns. 
Figure 1a. Employment, Greece, 1980 - 2011

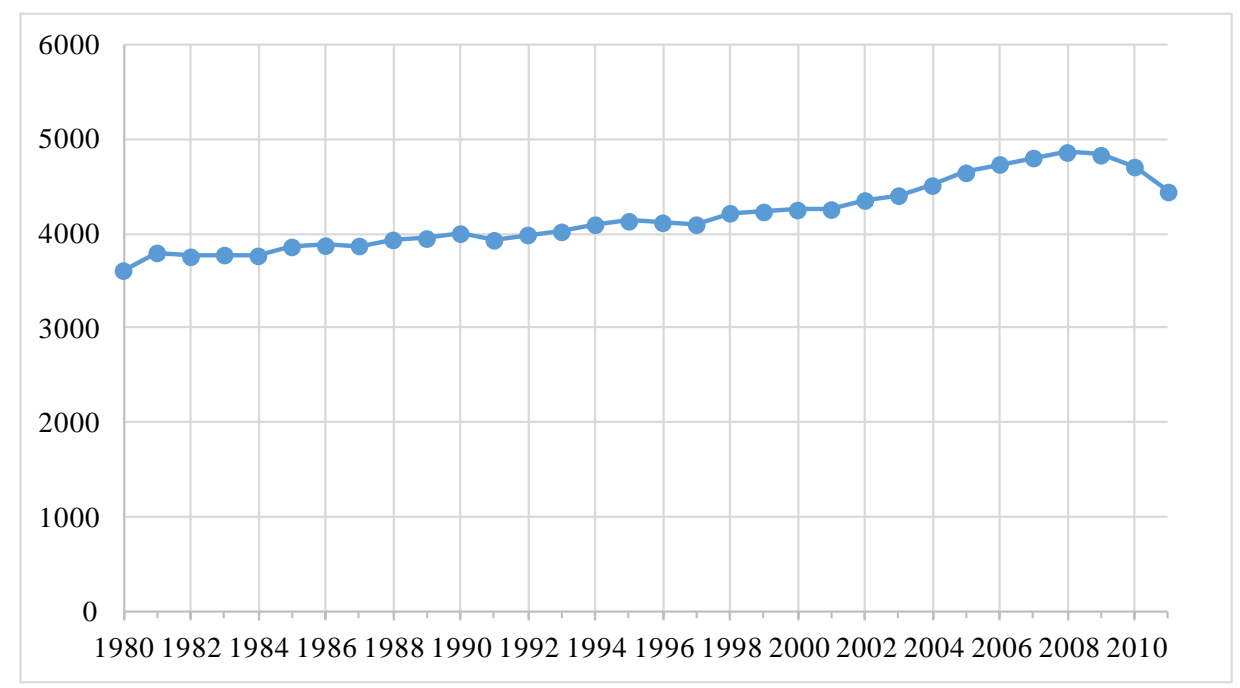

Legend: Based on the European University Institute (EUI) European Regional Dataset (ERD). The data is a country-level aggregate of the NUTS3 information for Greece, covering the period 1981 - 2013. All data on gross value added are in millions of euro for 2005.

Source: authors' calculations.

Figure 1b. Employment per Sector, Greece, 1980 - 2011

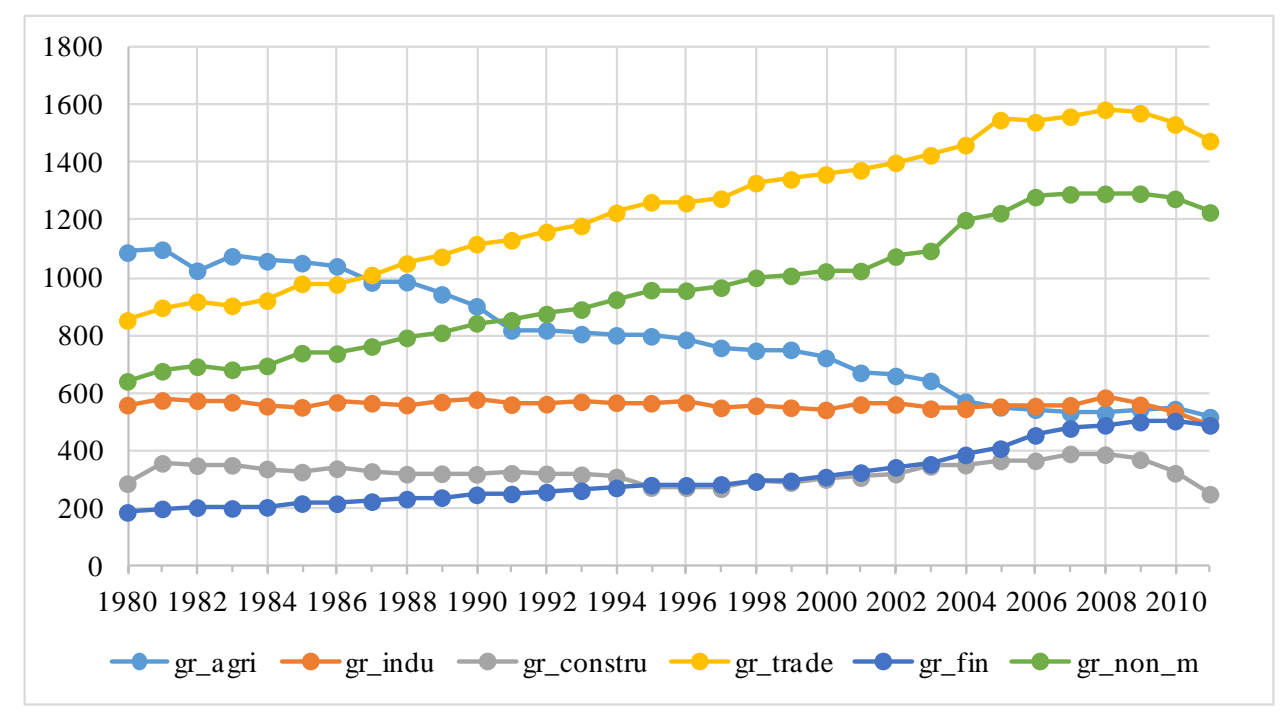

Legend: Based on the same EUI-ERD data as Figure 1a. The graph represents the breakdown of employment per sector, namely: gr_agri - agriculture, gr_ind - industry excluding manufacturing, gr_constr - construction, gr_trade - wholesale, retail, transport and distribution, communications, hotels and catering, gr_fin - financial and business services, gr_non_m - non-market services (Tiboutian intangible investment specialization). Source: authors' calculations.

These results offer reasonable justification for employing model (1) for our prediction purposes. In addition, we can check the correlation coefficients between the dependent and explanatory variables intended to be inferred in the model. Table 1 presents the correlations. 
Table 1. Correlations between the main variables

\begin{tabular}{|c|c|c|c|c|c|c|c|c|c|c|c|c|}
\hline & ln_gva & ln_empl & gva & empl_ts & si_agri & si_constr & si_fin & si_indu & si_non_m & si_trade & s_byza e & S_cast $\sim \mathrm{s}$ \\
\hline ln_gva & 1 & & & & & & & & & & & \\
\hline ln_empl & 0.96 & 1 & & & & & & & & & & \\
\hline gva & 0.71 & 0.67 & 1 & & & & & & & & & \\
\hline empl_ts & 0.74 & 0.72 & 0.99 & 1 & & & & & & & & \\
\hline si_agri & -0.51 & -0.44 & -0.36 & -0.38 & 1 & & & & & & & \\
\hline si_constr & -0.26 & -0.30 & -0.19 & -0.20 & 0.05 & 1 & & & & & & \\
\hline si_fin & 0.10 & 0.10 & 0.37 & 0.36 & -0.21 & -0.16 & 1 & & & & & \\
\hline si_indu & 0.31 & 0.27 & 0.23 & 0.24 & -0.04 & -0.15 & 0.18 & 1 & & & & \\
\hline si_non_m & -0.09 & -0.10 & 0.13 & 0.11 & 0.04 & 0.01 & 0.31 & 0.10 & 1 & & & \\
\hline si_trade & 0.34 & 0.26 & 0.27 & 0.28 & -0.45 & 0.15 & -0.02 & -0.13 & -0.28 & 1 & & \\
\hline s_byzantine & 0.14 & 0.03 & 0.09 & 0.07 & -0.39 & 0.13 & -0.09 & -0.24 & -0.12 & 0.43 & 1 & \\
\hline S_castles & 0.06 & 0.01 & 0.04 & 0.03 & -0.29 & 0.05 & -0.15 & -0.32 & -0.19 & 0.41 & 0.75 & 1 \\
\hline
\end{tabular}

Note: The table presents the correlation coefficients between the main variables in our dataset, grouped into 3 groups: (i) main dependent and explanatory variable respectively ln empl - logarithm of employment and ln gva - logarithm of gross value added; (ii) the dummies on specialization of employment in a particular sector, respectively in: si_agri - agriculture, si_ind - industry excluding manufacturing, si_constr - construction, si_trade - wholesale, retail, transport and distribution, communications, hotels and catering, si_fin-financial and business services, si_non_m - non-market services (Tieboutian intangible investment specialization) (source of the data is the EUI ERD), (the correlations are for the period 1980-2011; (iii) two cultural heritage related variables - these are the number of temples per square meter remaining from Byzantine times as well as the share of castles from all historic periods (source: the Hellenic Ministry of Culture Permanent List of Designated Archaeological Sites and Monuments in Greece listedmonuments.culture.gr).

Source: authors' calculations. 
Table 1 shows indeed that the logarithm of gross value added explains almost fully the local employment, which means that our model (1) is not underspecified. Next, the specialization dummies seem also to exhibit a reasonable correlation with the dependent variable and serve the purpose of our estimations. The cultural variables seem to be more related to the specialization variables than to the dependent variable. On one side, this is a sign of confirmation of the Tieboutian rationale. We observe that culture, and the Tieboutian intangible investment related trade and non-market services specialization, seem to have a high correlation. The correlation with the dependent variable is rather low. While this might not be ideal for a joint inference of culture and specialization, it may be seen as a perfect case for a 'horse race' between the cultural variables and the intangible investment related variables which can confirm or deny the cultural origin of the effect of these two source of impact. This is one of many alternative ways to test the cultural origins of intangible investment effects, but the present one is among the most clear-cut ones.

As the focus of this paper is on the cultural influence on regional development in the case of an economic shock, we first make a prediction model using model (1) and a regression with fixed time and regional effects. With the obtained coefficients for model (1), we derive the forecast and then infer the forecast errors (i.e. the difference between predicted values and actual values during the crisis) with model (2) to explore the sources for the irregularities that occurred under the economic shock. Table 2 below presents the operationalization of model (1) using an OLS regression to obtain predicted values of the logarithm of regional employment ln_empl cleaned from irregularities and deseasonalized:

Table 2. Historic trend prediction - stochastic forecast base model

\begin{tabular}{|c|c|c|c|c|c|c|}
\hline \multirow{3}{*}{$\begin{array}{l}\text { dep.var. } \\
\text { ln_gva }\end{array}$} & \multicolumn{6}{|c|}{ ln_empl } \\
\hline & \multirow{2}{*}{$\begin{array}{c}\text { Coef. } \\
0.996\end{array}$} & \multirow{2}{*}{$\begin{array}{r}\text { Std.Err. } \\
0.008\end{array}$} & \multirow{2}{*}{$\frac{\mathrm{t}}{125.34}$} & \multirow{2}{*}{$\frac{P>|t|}{0.0000}$} & \multicolumn{2}{|c|}{ [95\% Conf. Interval] } \\
\hline & & & & & 0.9805 & 1.0117 \\
\hline si_agri & 0.153 & 0.019 & 8.18 & 0.0000 & 0.1163 & 0.1897 \\
\hline si_constr & -0.089 & 0.014 & -6.24 & 0.0000 & -0.1173 & -0.0612 \\
\hline si_fin & -0.085 & 0.024 & -3.47 & 0.0010 & -0.1325 & -0.0368 \\
\hline si_indu & -0.182 & 0.019 & -9.43 & 0.0000 & -0.2200 & -0.1442 \\
\hline si_non_m & 0.088 & 0.018 & 5.01 & 0.0000 & 0.0535 & 0.1223 \\
\hline si_trade & -0.052 & 0.015 & -3.58 & 0.0000 & -0.0808 & -0.0236 \\
\hline _cons & -3.25 & 0.065 & -49.93 & 0.0000 & -3.3785 & -3.1231 \\
\hline Time FE & \multicolumn{6}{|c|}{ Yes } \\
\hline Space FE & \multicolumn{6}{|c|}{ Yes } \\
\hline $\mathrm{F}$ & \multicolumn{6}{|c|}{$(8,1419)=2422,02$} \\
\hline Prob $>$ F & \multicolumn{6}{|c|}{0.0000} \\
\hline R-sq & \multicolumn{6}{|c|}{0.93} \\
\hline Root MSE & \multicolumn{6}{|c|}{0.254} \\
\hline $\mathrm{N}$ & \multicolumn{6}{|c|}{1428} \\
\hline
\end{tabular}

Note: The table presents the results from an OLS regression with space and region fixed effects on the basis of which the stochastic prediction and the main forecasts under analysis in the current paper are generated. Source: authors' calculations.

Table 2 shows that model (1) and all its components demonstrate a high relevance for the prediction of the dependent variable of interest. The logarithm of gross value added together with a specialization in agriculture and in non-market services displays a positive trend in employment over the years. These results are rather realistic, as Greece is a country 
developing a service economy and enjoying a climate very favourable for agrarian activities such as olive oil production, for example. It is interesting to note the positive relationship between employment and specialization in exactly the most Tieboutian motivated sector - the one in non-market services.

We use now model (1) to estimate the OLS prediction model and obtain the coefficients based on which the forecast for $2008-2011$ is derived. Next, we obtain the forecast errors and address them with model (2). Table 3 shows the results, presenting our horse-race between the Tieboutean (living culture) and cultural heritage related variables in explaining the forecasting error. In the 'horse race', we addressed the model specifications: a) with only sectoral specializations, b) with specialization in all sectors excluding the trade and nonservice related ones, while including alternatively one of the cultural variables, and c) finally we are 'horse-racing' the Tiebotean culture driven intangible investments specialization and the cultural heritage as persistence by putting together all the specialization dummies and the cultural variables. We see a strong relationship between non-market services and cultural heritage variables. The cultural variable s_castles even manages to outperform the Tieboutean non-market services specialization, which is an indication in favour of the cultural origin of public (intangible) investment related sectors.

Table 3 presents the examination of the main factors for the deviations of the actual values from the forecasted values during the period of crisis, operationalizing the culturally augmented model (2). This means that the results can be interpreted as follows. First, the financial sector specialization seems to be the one which leads to most employment irregularities during the crisis as well as to the general gross value added decrease. Specialization in trade and non-monetary services seems to be associated with a negative relationship with the error, which means these regions specialized in Tieboutian intangible investment were more sustainable and less affected by the crisis and even performed better than the model would predict. Second, the positive sign of the cultural variables in this context means two things: (i) it indicates possible cultural persistence effects on local development in Greece; (ii) it may be due to reverse causality, where that cultural tourism may have the potential to generate employment, but requires solid investments in the maintenance of cultural heritage which is the main capital for cultural tourism operation.

In a last step, we have explored the possibility of using culture in the prediction model. Table 4 below presents the comparison between the predictive models excluding and including culture, respectively. 
Table 3. Horse-racing culture in forecast error - cultural resistance to economic shock

\begin{tabular}{|c|c|c|c|c|c|c|}
\hline \multirow[t]{2}{*}{ dep.var. } & \multicolumn{6}{|c|}{ "u_forecast_ln_empl } \\
\hline & coef. & t-value & coef. & t-value & coef. & t-value \\
\hline ln_gva & 0.227 & 2.58 & 0.236 & 2.63 & 0.250 & 2.78 \\
\hline si_agri & 0.053 & 0.33 & 0.166 & 0.95 & 0.176 & 0.99 \\
\hline si_constr & 0.185 & 1.14 & 0.179 & 1.10 & 0.215 & 1.36 \\
\hline si_fin & 0.496 & 2.19 & 0.549 & 2.44 & 0.583 & 2.55 \\
\hline si_indu & -0.217 & -1.02 & -0.181 & -0.81 & -0.134 & -0.60 \\
\hline si_non_m & -0.361 & -2.02 & -0.366 & -2.02 & -0.353 & -1.94 \\
\hline si_trade & -0.468 & -3.53 & -0.530 & -3.99 & -0.582 & -3.95 \\
\hline s_byzantine & & & 1.048 & 2.60 & & \\
\hline S_castles & & & & & 82.888 & 2.47 \\
\hline _cons & -2.888 & -1.36 & -1.798 & -2.61 & -2.016 & -2.88 \\
\hline Time FE & $\mathrm{Y}$ & & & & $Y$ & \\
\hline Space FE & Y & & & & 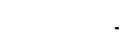 & \\
\hline $\mathrm{F}$ & $(8,195)$ & & $(11,192$ & & $(11,192$ & \\
\hline Prob $>$ F & 0.0 & & 0.0 & & 0.0 & \\
\hline R-sq & 0 . & & & & 0. & \\
\hline Root MSE & 1.0 & & 1.0 & & 1.0 & \\
\hline $\mathrm{N}$ & 20 & & & & 20 & \\
\hline
\end{tabular}

Note: The table presents the results of an ordinary least square regression for the error of forecast 2008-2011 of logarithm of employment in three specifications: (i) with time and space fixed effects, explained by actual levels of specialization; (ii) with time fixed effects, explained by actual levels of specialization and fixed cultural characteristics of the milieu approximated through a historic period specific instrumental variable - share of byzantine cultural heritage per square kilometer; (iii) with time fixed effects, explained by actual levels of specialization and fixed cultural characteristics of the milieu approximated through a holistic instrumental variable - share of historic castles from all periods (per square kilometer).

Source: authors' calculations.

As Table 4 shows, the predictive power of the models is almost the same with or without including culture in the prediction, while the irregularities in the forecast errors, which occur during the shock period of the economic crisis, were found related to culture. According to the Cambridge 'mixed-method of triangulation' (see Downward and Mearman 2007), the meaning of the two results: (i) lack of improvement of the predictive power of the model when culture is involved in it and (ii) the horse-race experiment results confirming culture as a factor explaining the forecast error for the period of the crisis, is that they jointly confirm that culture is a driving factor for the irregularities in local employment under a condition of economic shock. 
Table 4. Comparison of stochastic predictions with and without culture

\begin{tabular}{|c|c|c|}
\hline $\begin{array}{l}\text { Stochastic1: } \\
\text { specialization indeces }\end{array}$ & Linear regression & 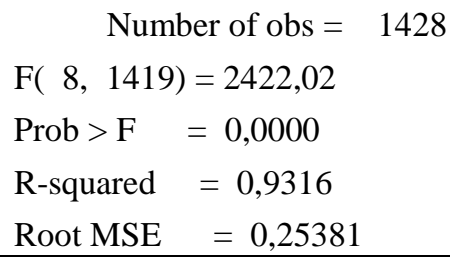 \\
\hline $\begin{array}{l}\text { Stochastic2: } \\
\text { specialization indeces } \\
\text { s_byzantine }\end{array}$ & Linear regression & 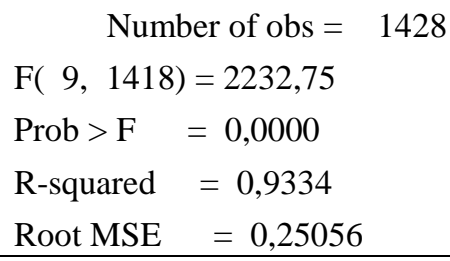 \\
\hline $\begin{array}{l}\text { Stochastic3: } \\
\text { specialization indeces } \\
\text { s_castles }\end{array}$ & Linear regression & 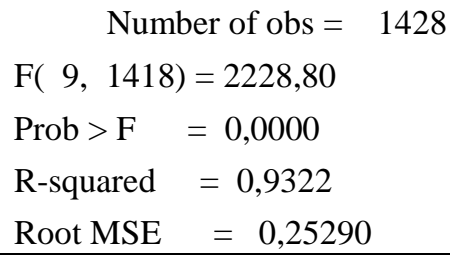 \\
\hline
\end{tabular}

Note: The table presents the descriptive statistics with accent to root mean square error (RMSE) for stochastic prediction of logarithm of employment for the period 1980 - 2007 as a function of: sector specialization (model Stochastic1), sector specialization and concentration of Byzantine cultural heritage per square kilometer (model Stochastic2), sector specialization and share of castles from all historic periods per square kilometer (model Stochastic3).

Source: authors' calculations.

\section{Concluding remarks}

The results of our current study present intriguing evidence for the importance of culture as a source of sustainable development in economic shock conditions. Our analysis is based on classical estimation techniques, but it applies these to a big regional dataset with over 1600 observations and identifies effects that are genuinely worth further exploration with more advanced methods.

\section{References}

Acemoglu, D. and Robinson, J. (2010) The role of institutions in growth and development, Review of Economics and Institutions, 1(2), 1-33.

Angulo, A., Mur, J. and Trivez, J. (2014) Forecasting heterogeneous regional data: the case of Spanish employment, Economics and Business Letters, 3(4), 263-275.

Dell, M. (2010) The persistent effects of Peru's mining mita, Econometrica, 78(6), 18631903.

Downward, P. and Mearman, A. (2007) Retroduction as mixed-methods triangulation in economic research: reorienting Economics into social science, Cambridge Journal of Economics, 31(1), 77-99.

Florida, R. (2005) The flight of the creative class: the new global competition for talent, London: Harper Collins.

Florida, R. (2002a) The rise of the creative class: and how it's transforming work, leisure, community, and everyday life, Basic Books: New York. 
Florida, R. (2002b) Bohemia and economic geography, Journal of Economic Geography, 2(1), 55-71.

Jacobs, J. (1961) The death and life of great American cities, New York: Vintage.

Pedroni, P., Sheppard, S. and Wilson, N. (2012) Culture shocks and consequences: the connection between the arts and urban economic growth, Department of Economics Working Papers 2012-04, Department of Economics, Williams College.

Romer, P. (1986) Increasing returns and long-run growth, Journal of Political Economy, 94(5), 1002-1037.

Romer, P. (1990a) Endogenous technological change, Journal of Political Economy, 98(5), 71-102.

Romer, P. (1990b) Capital, labour and productivity, Bookings Papers on Economic Activity, Microeconomics, 337-367.

Romer, P. (1994) The origins of endogenous growth, The Journal of Economic Perspectives, 8(1), 3-22.

Schumpeter, J.A. (1939) Business cycles. A theoretical, historical and statistical analysis of the capitalist process, 2 vols., London: McGraw-Hill Book Co.

Shaoa, Q. and Nib, P. (2004) Least-squares estimation and ANOVA for periodic autoregressive time series, Statistics and Probability Letters, 69(3), 287-297.

Tiebout, C. (1956) A pure theory of local expenditures, Journal of Political Economy, 64(5), $416-424$.

Tubadji, A. (2012) Culture based development - culture as an encompassing economic factor: empirical evidence for Germany, International Journal of Social Economics, 39(9), 690-703.

Tubadji, A. (2013) Culture-based development: culture and institutions - Economic development in the regions of Europe, Journal of Society Social Science, 5(4), 355391.

Tubadji, A. and Gnezdilova, N. (2015) The cultural root of the German job miracle, International Journal of Social Economics, 41(11), 1014-1037.

Tubadji, A. and Nijkamp, P. (2014) Altruism to strangers for our own sake: immigration impact on productivity and its dependence on local culture, International Journal of Manpower, 35(1/2), 11-32.

Tubadji, A. and Nijkamp, P. (2015) Cultural gravity effects among migrants: a comparative analysis of the EU15, Economic Geography, forthcoming. 